\title{
Spatiotemporal effects of proximity to metro extension on housing price dynamics in Manhattan, New York City
}

\author{
ChengHe Guan \\ New York University Shanghai \\ chenghe.guan@nyu.edu
}

\author{
Richard Peiser \\ Harvard University Graduate School of \\ Design \\ rpeiser@gsd.harvard.edu
}

\author{
Mark Junjie Tan \\ University of Oxford \\ junjie.tan@gtc.ox.ac.uk
}

\begin{abstract}
Investment in public transportation such as a metro line extension is often capitalized partially into housing values due to the spatiotemporal effects. Using housing transaction data from 2014 to 2019, this paper studies the Second Avenue Subway or Q-line extension in New York's City's Manhattan borough. Multiple metro station catchment areas were investigated using spatial autocorrelationcorrected hedonic pricing models to capture the variation of housing price dynamics. The results indicate that properties in closer proximity to the Q-line extension received higher price discounts. The effect varied by occupancy type and building form: condominiums experienced the highest price discount, while walk-up and elevator co-ops experienced a price premium. After controlling for location variations, we observed price discounts on the westside and price premiums on the eastside of the Q-line. Residential properties within $150 \mathrm{~m}$ west to the Q-line extension received the highest price discount post operation, while on the eastside, properties in the same proximity received the highest price premium. The anticipation effect varies by distance to metro extension stations, both before and after the operation of metro line extension. We discuss the disruption of metro construction on the housing market depending on housing type, location variation, and changes over time.
\end{abstract}

Keywords: Market anticipation, spatial variation, Metro line extension, housing price, New York City

\section{Article history:}

Received: October 26, 2020

Received in revised form: April

19, 2021

Accepted: September 20, 2021

Available online: December 6,

2021

\section{Introduction}

The effects of metro extensions on real estate pricing have been widely studied. Conventional urban economic theory suggests that real estate housing prices decline as a function of the distance to the central business area where jobs are located (Alonso, 1964; Devaux et al., 2017; Diao, 2015; McMillen, 2006). Therefore, a reduction of travel time saving through proximity to new metro stations should be translated into higher land and property values (Kaneko et al., 2019; Spears et al., 2017; Valente et al., 2005). However, there is no consensus on the expected impacts, ranging from negative to positive

Copyright 2021 ChengHe Guan, Junjie Tan \& Richard Peiser http://dx.doi.org/10.5198/jtlu.2021.1915

ISSN: 1938-7849 | Licensed under the Creative Commons Attribution - Noncommercial License 4.0

The Journal of Transport and Land Use is the official journal of the World Society for Transport and Land Use (WSTLUR) and is published and sponsored by the University of Minnesota Center for Transportation Studies. 
(Devaux et al., 2017; Kim \& Lahr, 2014).

One challenge to accurately assess the effects of metro extensions on housing values is to distinguish housing types. Another challenge is to isolate the spatial variation of the impact, especially in large cities with complex metro networks -- for example, when metro extension encroaches into the catchment areas of existing metro stations. A third challenge is to recognize the temporal variation according to the implementation phases. The development of a new metro line is not instantaneous and anticipation or ripple effect is possible (Agostini \& Palmucci, 2009; Comber \& Arribas-Bel, 2017). The impact can vary over time and be heterogeneous among the stations (Devaux et al., 2017). Furthermore, housing values are location-dependent as a result of spatial autocorrelation. It is important to capture the latent spatial components (Anselin \& Bera, 1998). The concept of spatial autocorrelation is defined as "the coincidence between measures depending on location" (Anselin \& Bera, 1998; Devaux et al., 2017; Lesage \& Pace, 2009). Different from the standard regression, spatial autocorrelation recognizes the assumption of uncorrelated error terms and/or independent observations are violated.

This paper aims to assess the impact of the Second Avenue Subway or the Q-line extension in New York City on housing prices. Housing transaction data before (2014-2016) and after (2017-2019) the operation of the Q-line extension in January 2017 are used. In order to take account of spatial and temporal variations as well as spatial autocorrelation, multiple hedonic pricing models, spatial lag models, and spatial error models are implemented. The study investigates the following questions: (1) Was a significant marginal effect exerted on local real estate prices when metro line extension was announced? (2) What was the temporal variation of the marginal effect of housing value and was there any anticipation effect observed throughout the study period? 3) Were there any spatial autocorrelation and variation of the pricing effect in close proximity to the newly constructed metro stations?

The rest of the paper is organized as follows: the next section reviews previous studies of the effects of mass transit on real estate property values. The third section introduces empirical methodologies. The fourth section shows the statistical summary of transaction data after controlling for extreme data points and inflation. The fifth section addresses the occupancy type, spatial, and temporal challenges. The last section presents conclusions and limitations.

\section{$2 \quad$ Literature review}

\subsection{Effects of metro transit accessibility on housing price}

The effect of metro stations on surrounding property values has been well studied in recent years. While scholars have provided empirical evidence of positive effects between metro transit accessibility and real estate price, there are also studies showing negative effects or insignificant results in certain types of properties or neighborhoods (Cervero, 2006; Guan \& Rowe, 2021; Hsieh \& Noonan, 2018; McDonald \& Osuji, 1995; Rodriguez \& Mojica, 2009).

It is frequently hypothesized that metro stations would result in a positive effect on the surrounding real estate market. Results indicating positive correlation often appear more frequently than results with a negative association. Landis et al. (1995) find a $\$ 4.36$ price premium per meter close to transit stations in California. Cervero (2006) presents positive effects of commuter rail in San Diego. Also, in a study of San Diego, Duncan (2008) finds that condominiums receive more than 10\% in price capitalization benefits. Dube et al. (2013) show price premiums for houses located within walking distance to rail stations in Montreal. Kopczewska and Lewandowska (2018), in a study in London, suggest that every 100 $\mathrm{m}$ closer to the metro station costs $0.7 £$ per square foot per year. Xu et al. (2016) investigate the effect of transit access on commercial property in Wuhan, China, and find a positive price premium of $16.7 \%$ 
for the $0-100 \mathrm{~m}$ core area and $8.0 \%$ within the $100-400 \mathrm{~m}$ radius.

There are also studies that discover a negative effect of metro stations on property values. Hess and Almeida (2007) find proximity effects to light rail are negative in low-income station areas in Buffalo, New York. Dai et al. (2016) find that real estate markets can experience a negative impact, and that transfer stations are greater than the non-transfer stations in Beijing. Lin et al. (2018) discover a negative impact of light rail stations on industrial and rural development areas but not in the residential and commercial areas. The negative impact can be stemming from noise or air pollution or other discomforts (Kopczewska \& Lewandowska, 2018). Moreover, there are also studies showing insignificant results of metro stations on property values (Liou et al., 2016; Wang et al., 2016; Zhang et al., 2016).

\subsection{Housing type, market anticipation, and spatial variation}

The effect of metro lines on housing prices can vary by housing types (Atkinson-Palombo, 2010; Deng \& Chen, 2019; Guan \& Peiser, 2018; Zhong \& Li, 2016). Even in the same location, the effects of new metro stations on different types of housing can vary. In a study of the Los Angeles property sale market, Zhong and $\mathrm{Li}$ (2016) divided housing types into single-family, multi-family, and Condominium. While they found proximity to transit stations benefit multi-family housing, the effect is the opposite to single-family housing. Miller et al. (2018) investigated the effect of property conditions and building forms on housing prices. They found type of construction or building form is a significant factor for the U.S. market. Housing type in New York City varies by occupancy type as well as building form - condominiums or co-ops, high-rise or low rise, etc. In this study, we consider housing type variations in the evaluation of the effects of metro stations on housing prices. In the study area of the Q-line extension, we categorized housing property into four types of ownerships (Condominiums, walk-up co-ops, elevator co-ops, and others), see Appendix A.

Anticipation and post-construction (or time lag) effects occur for many reasons: Uncertainty of the locations of the metro station; the probability that the project is canceled during the construction period, or expected accessibility improvement (McDonald \& Osuji, 1995). The impacts of a major metro construction project on housing values can alter according to anticipation and post-construction effects of the market (Devaux et al., 2017). It is important to address each distinct implementation phase (Devaux et al., 2017). Agostini and Palmucci (2008) divided the impact into three distinct phases: announcement (pre-construction) period; construction period; and operation period. During the announcement period, speculation can be observed indicating a first market response or anticipation (Agostini and Palmucci, 2008; Devaux et al., 2017). During the post-construction period, the impact variation could be the result of the service maturity (Devaux et al., 2017). Harjunen (2018) studied a new metro line in Helsinki, the West Metro. He found that during the construction period, real estate markets already adjusted to the evidence about the mass transit investment. For example, five years ahead of the operational phase, apartments within an 800-m radius area from the metro stations exhibited a four percent price premium (Harjunen, 2018). In this study, we merge the announcement and construction periods.

\subsection{Estimation methods}

The most common analytical method of studying the effects of metro stations on surrounding property prices is using hedonic regression techniques. Martinez and Viegas (2009) studies the relationship between transportation infrastructure and housing prices in London using hedonic pricing models. Pan et al. (2014) uses a hedonic pricing model to compare the differences between metro price premiums in Shanghai and Houston. However, Devaux et al. (2017) stated that the presence of spatial latent component is crucial for results accuracy. The advancement of spatial econometrics and spatial statistics 
has provided many spatial analytical tools such as geographically weighted regression (GWR) models to address spatial autocorrelation in hedonic pricing models (Cao et al., 2019). Debrezion et al. (2011) adopted a GWR model to study three metropolitan areas in the Netherlands. Diao et al. (2017) employed a spatial lag difference-in-difference model to study the private housing market in Singapore. In this study, we applied both spatial lag and spatial error terms to test for spatial autocorrelations. In addition, we divided the location into the eastside and westside of the Q-line extension. Furthermore, we control the effect of existing metro lines by adding distance dummy variables.

\subsection{Study on New York City}

Several papers have focused on housing prices and metro stations in the New York City area (Kay, 2014; Lewis-Workman \& Brod, 1997). Kay et al. (2014) investigate the price premium effect of metro stations at New Brunswick and Newark using hedonic regression analysis. Results indicate that the mix-used development in Transit-Oriented Development (TOD) areas and stations with direct access to New York City are more likely to be valued higher than others. Kim and Lahr (2014) study the effect of the Hudson-Bergen light rail on surrounding residential property prices using repeat-sales data. They find that stations furthest from the local center business district experience the highest price premiums. The premiums become insignificant beyond $400 \mathrm{~m}$ from the stations. In our study that focuses on the Qline extension in Manhattan, a pre-existing metro line (the Lexington Ave line) is located two blocks west of the Q-line extension line. Such pre-existing conditions provided additional metro access to the west of the Q-line extension stations, yielding different metro accessibility than to the east of the Q-line extension. Therefore, in order to distinguish the location variation, we implemented a locational division that divides the west side and east side of the Q-line extension to better capture the marginal value effect exerted on the study area.

Overall, there is a broad literature examining the addition of metro lines from the peripheral to the metropolitan center. However, limited research has investigated the impact of additional metro access to wealthy neighborhoods in the center of a major global city with well-established metro systems already in place. Moreover, limited literature examined the variation that existed in both spatiotemporal dimension and housing types aspects in a single study. Therefore, the present research focuses on the addition of the Q-line extension in the upper east side, as it is the only metro extension in Manhattan in recent decades, and analyzes the marginal value effect of the impact on multiple housing typologies across the duration of metro construction and operation.

\section{$3 \quad$ Methodology}

\subsection{Study area}

The study area is the catchment areas of the Q-line extension (CAQE) in Manhattan, New York City. The CAQE is located in the residential Upper East Side, an area with a mix of classic brownstones and high-rise buildings. The CAQE encroaches on both Yorkville and Lenox hill neighborhoods. Figure 1 shows the New York City Subway network with the portion of the Q-line extension highlighted and the catchment areas within walking distance $(750 \mathrm{~m})^{1}$ to the stations. In January 2017 , three stations at 72nd street, 86th street, and 96th street opened, connecting to the Broadway Line (BMT) via 63rd street.

${ }^{1}$ A $750 \mathrm{~m}$ buffer effectively covers the majority of the upper east side area and the adjacent existing metro line. Additionally, it excludes the properties directly located at the edge of the Central Park, which can maintain price premium from the view to the park that we have no variables to control for. 


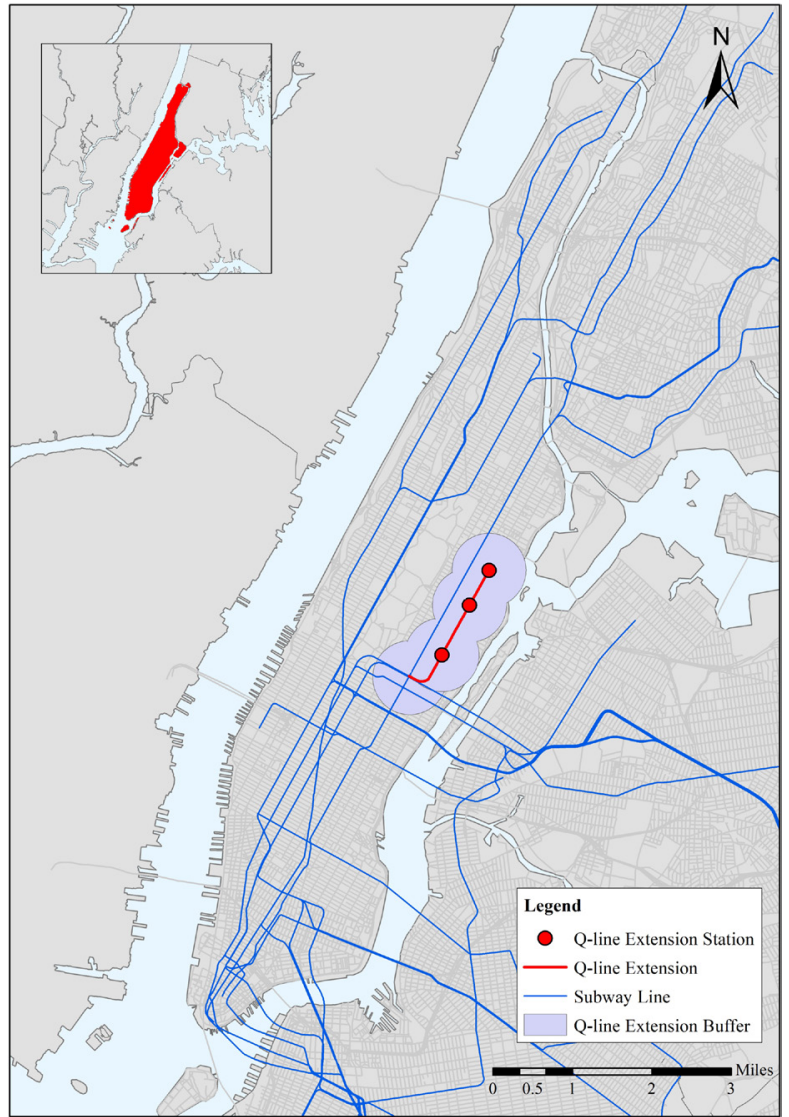

Figure 1. New York City subway network and the catchment areas of the Q-line extension in Manhattan.

\subsection{Data collection}

Individual property transaction data is collected from the Department of Finance, New York City (Department of Finance, 2019). The rolling sales data lists properties sold in the last twelve-month period with information that contains neighborhood, buildings, address, date, and price. A python script is written to translate the listed address into a coordinated system. The algorithm logic behind the script is to input an excel sheet of addresses to MapQuest, where the server will return various raw data that include the coordinates. Then a new excel sheet is generated to extract the coordinates as output. The coordinates generated from the MapQuest are slightly different from Google Maps, with a discrepancy of no more than $5 \mathrm{~m}$.

Housing prices are categorized into three components: (1) structural characteristics; (2) amenity characteristics; and (3) neighborhood characteristics (Diao, 2015; Miller et al., 2018). In addition, we separated proximity to metro as the fourth component. In this component, we use five dummy variables to represent proximity to metro stations: 0-150, 150-300, 300-450, 450-600, and 600-750 m, see Appendix B. Six variables are selected for the structural characteristics, seven for the amenity characteristics, and six for the neighborhood characteristics. We also include two variables -- distance to Central Park and to the East River, to address the impact of these large public attractions.

\subsection{Research design}

To quantify the spatial and temporal variation of price dynamics, we applied the following methods: 
First, we test price change and frequency variation between the whole market and the vicinity of the metro stations. Second, we run hedonic pricing models to investigate significant variables affecting housing prices in the vicinity of the metro stations. Third, we run additional OLS regression models to investigate occupancy type, spatial, and temporal variations. The hedonic pricing model is taken from Miller et al. (2018) as follows:

$\ln P_{i t}=\sum_{j=1}^{J} \beta_{i} X_{i j}+\sum_{k=1}^{K} \beta_{k} Y_{k}+\sum_{l=1}^{L} \beta_{l} Z_{l}+\sum_{m=1}^{M} \beta_{m} U_{m}+\varepsilon_{i}$

Where $X i j$ is the $j$ th structural characteristic variable for observation $i$ at time $t, Y$ is a set of amenity variables, $Z$ is a set of neighborhood characteristics, and $U$ is a set of binary variables for proximity.

The hedonic pricing model as specified in equations (1) does not account for spatial autocorrelation (Diao et al., 2015). To correct for spatial autocorrelation, we add two types of spatial autoregressive terms to equation (1). The first type of is a spatially lagged dependent variable. The spatial lag model is as follows:

$\ln P_{i t}=\rho W_{l n P}+\sum_{j=1}^{J} \beta_{i} X_{i j}+\sum_{k=1}^{K} \beta_{k} Y_{k}+\sum_{l=1}^{L} \beta_{l} Z_{l}+\sum_{m=1}^{M} \beta_{m} U_{m}+\varepsilon_{i}$

where $W \ln P$ is the spatial-lag variable and $\rho$ is a spatial-lag correlation parameter. For the second type of spatial autocorrelation, we assume that the housing attributes captured by the model have only local effects but factors that are missing from the model specification are spatially correlated (Diao et al., 2015). We added a spatially lagged error term to the model as follows:

$\ln P_{i t}=\rho W_{l n P}+\sum_{j=1}^{J} \beta_{i} X_{i j}+\sum_{k=1}^{K} \beta_{k} Y_{k}+\sum_{l=1}^{L} \beta_{l} Z_{l}+\sum_{m=1}^{M} \beta_{m} U_{m}+\varepsilon_{i}$

$\varepsilon_{i}=\tau V_{\varepsilon}+\mu_{i}$

where $\varepsilon_{i}$ is the weighted average of error terms in neighboring areas, $\tau$ is a spatial error correlation parameter, and $\mu$ is a standard normal error. The spatial weights matrix used are row-standardized, taking the given binary zero-one weights and divided by the row sum (Anselin \& Bera, 1998).

\section{$4 \quad$ Results}

\subsection{Description of variables}

In the first round, we collected property transaction data in Manhattan. The description of the statistics of housing transactions in Manhattan between 2014-2019 is shown in Table 1. After removing transaction with incomplete information, the total number of transactions collected is 81,241 . The mean of properties sold is $\$ 2.576$ million, and the price distribution is skewed to the right, indicating the existence extreme values (very low or very high). For reference, the median household income in Manhattan is $\$ 66,739$ according to New York City Census. The majority of the properties sold during this period are residential housing including condos, co-ops, and single-family housing. The building classification is based on the standard administrative classification from the City of New York (City of New York, 2019). In the second round, we focused on the CAQE areas. This time, we also collected prices per square foot and other built environment variables. To better understand the distribution of housing property sales in the study area, we plotted a histogram of all transactions and observe that there are very low and very high transaction prices. These extreme values can significantly affect the results of our study. We eliminated housing sales that are either below $\$ 300$ or above $\$ 5,000$ per square foot. We also 
adjusted for inflation using the Consumer Price Index (CPI): Housing for the United States to control inflation rate: $233.215,238.061,243.974,251.230$, and 258.479 from 2014 to 2018, respectively. We use "CPI of Current Year/CPI of Prior Year * Prior Year Value" to calculate Current Year Value.

The descriptive statistics of all transactions within the CAQE are summarized in Table 2. After removing commercial units, storage, parking, and data aggregated to represent the entire building of all types (we did not include building type conversions), we categorized residential properties into walkup co-ops, elevator co-ops, condominium, single-family dwelling, and duo-family dwelling. There are 20,050 residential transactions included. The housing market's quarterly price dynamics have been used to understand the time fixed effect and analyze price variations of properties over the study period (Devaux, 2017; Diao et al., 2017; Gordon \& Winkler, 2019). We observed the mean housing prices over the eighteen quarters from 2015 to the second quarter of 2019, see Figure 2. A visual examination shows that the trend of price change in the CAQE does not resemble the Manhattan market. Before the operation of the Q-line extension, the Manhattan market had higher price fluctuation than the CAQE. After the operation of the Q-line extension, the CAQE has more price variations than the Manhattan market. Thus, the assumption that the changes of price pattern before and after the Q-line extension diverge from the Manhattan market is valid. Further investigation into the anticipated impact on housing prices is needed. We then break down the mean housing price by housing category, and the same results hold for walkup co-ops, elevator co-ops, and condominiums.

Table 1.Descriptive statistics of property sales in Manhattan, New York City, 2014-2019

\begin{tabular}{lcccccc}
\hline & $\begin{array}{c}\text { All } \\
\text { Transactions } \\
(\text { TXN) }\end{array}$ & $\begin{array}{c}\text { Walkup } \\
\text { Co-ops }\end{array}$ & $\begin{array}{c}\text { Elevator } \\
\text { Co-ops }\end{array}$ & $\begin{array}{c}\text { Condominium } \\
\text { One Family } \\
\text { Dwelling }\end{array}$ & $\begin{array}{c}\text { Two Family } \\
\text { Dwelling }\end{array}$ \\
\hline Average Total Price $(\$)$ & $2,577 \mathrm{k}$ & $3,233 \mathrm{k}$ & $2,178 \mathrm{k}$ & $2,561 \mathrm{k}$ & $8,678 \mathrm{k}$ & $4,741 \mathrm{k}$ \\
No. of TXN in 2014 & 61,501 & 5,138 & 24,872 & 30,412 & 373 & 299 \\
No. of TXN in 2015 & 15,811 & 1,354 & 6,428 & 7,731 & 85 & 80 \\
No. of TXN in 2016 & 14,442 & 1,240 & 5,741 & 7,214 & 83 & 77 \\
No. of TXN in 2017 & 14,182 & 1,119 & 5,684 & 7,162 & 85 & 63 \\
No. of TXN in 2018 & 12,218 & 1,021 & 5,157 & 5,817 & 87 & 54 \\
No. of TXN in 2019 & 4,848 & 404 & 1,862 & 2,488 & 33 & 25 \\
\hline
\end{tabular}

Note: 2019 data only includes transactions before May. 
Table 2. Descriptive statistics of property sales within the catchment areas of Q-line extension stations, 2014-2019 (adjust ment for extreme values and inflations)

\begin{tabular}{|c|c|c|c|c|c|}
\hline Variables & Description & Mean & Std Dev & Min & $\operatorname{Max}$ \\
\hline \multicolumn{6}{|c|}{ Dependent Variable } \\
\hline Sale Price & Sale price per square foot & 1,380 & 662 & 305 & 5,000 \\
\hline \multicolumn{6}{|c|}{$\underline{\text { Structural Characteristic }}$} \\
\hline Area & Total area of unit in square feet & 1,320 & 1,050 & 225 & 15,000 \\
\hline Bath & Total number of bathrooms in unit & 1.83 & 1.12 & 0.50 & 11.00 \\
\hline Bed & Total number of bedrooms in unit & 1.87 & 1.11 & 1.00 & 10.00 \\
\hline Stories & Building stories & 21.78 & 12.13 & 1.00 & 96.00 \\
\hline Total Unit & Total number of units in building & 150.67 & 105.42 & 2.00 & 627.00 \\
\hline Age & Actual age of the building in years & 50.60 & 30.24 & 0.00 & 150.00 \\
\hline \multicolumn{6}{|c|}{$\underline{\text { Amenity Characteristic }}$} \\
\hline Amenity_G & Gym availability & 0.49 & 0.50 & 0.00 & 1.00 \\
\hline Amenity_P & Pool availability & 0.16 & 0.36 & 0.00 & 1.00 \\
\hline Amenity_Bi & Bike room availability & 0.67 & 0.47 & 0.00 & 1.00 \\
\hline Amenity_Ga & Garden availability & 0.06 & 0.24 & 0.00 & 1.00 \\
\hline Amenity_St & Storage space availability & 0.28 & 0.45 & 0.00 & 1.00 \\
\hline Amenity_Pa & Parking space availability & 0.36 & 0.48 & 0.00 & 1.00 \\
\hline Amenity_Pl & Children's playroom availability & 0.20 & 0.40 & 0.00 & 1.00 \\
\hline \multicolumn{6}{|c|}{ Neighborhood Characteristics } \\
\hline Dist_Cp & Distance to Central Park & 770.21 & 329.58 & 0.00 & $1,566.03$ \\
\hline Dist_Er & Distance to East River & 718.20 & 307.76 & 72.18 & $1,565.90$ \\
\hline Dist-Q & Distance to the nearest Q-line station & 414.29 & 174.05 & 2.21 & 749.70 \\
\hline Library & Library within $200 \mathrm{~m}$ & 0.15 & 0.35 & 0.00 & 1.00 \\
\hline Hospital & Hospital within $200 \mathrm{~m}$ & 0.05 & 0.21 & 0.00 & 1.00 \\
\hline \multicolumn{6}{|c|}{$\underline{\text { Proximity to Metro }}$} \\
\hline Q0_150 & Q line station $0-150 \mathrm{~m}$ & 0.08 & 0.26 & 0.00 & 1.00 \\
\hline Q150_300 & Q line station 150-300 & 0.18 & 0.39 & 0.00 & 1.00 \\
\hline Q300_450 & $Q$ line station $350-450 \mathrm{~m}$ & 0.33 & 0.47 & 0.00 & 1.00 \\
\hline Q450_600 & $\mathrm{Q}$ line station $450-600 \mathrm{~m}$ & 0.23 & 0.42 & 0.00 & 1.00 \\
\hline Q600_750 & $\mathrm{Q}$ line station $600-750 \mathrm{~m}$ & 0.17 & 0.38 & 0.00 & 1.00 \\
\hline A0-150 & Adj. station $0-150 \mathrm{~m}$ & 0.05 & 0.23 & 0.00 & 1.00 \\
\hline A150-300 & Adj. station $150-300 \mathrm{~m}$ & 0.14 & 0.35 & 0.00 & 1.00 \\
\hline A $300-450$ & Adj. station 300-450m & 0.24 & 0.43 & 0.00 & 1.00 \\
\hline
\end{tabular}




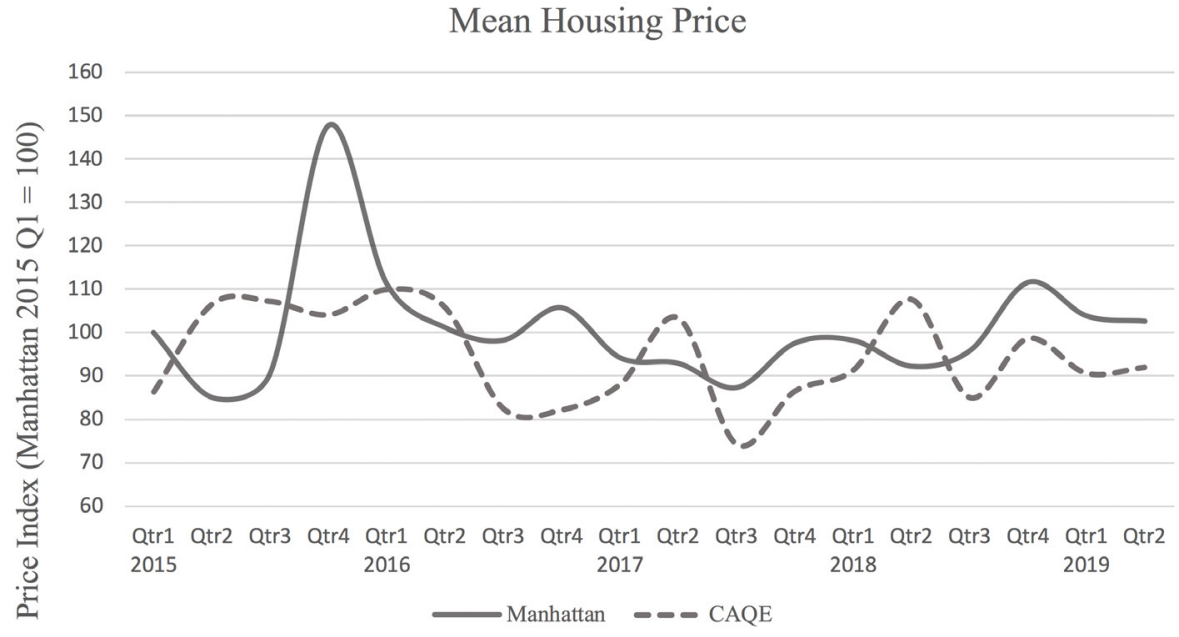

(a) CAQE versus Manhattan market

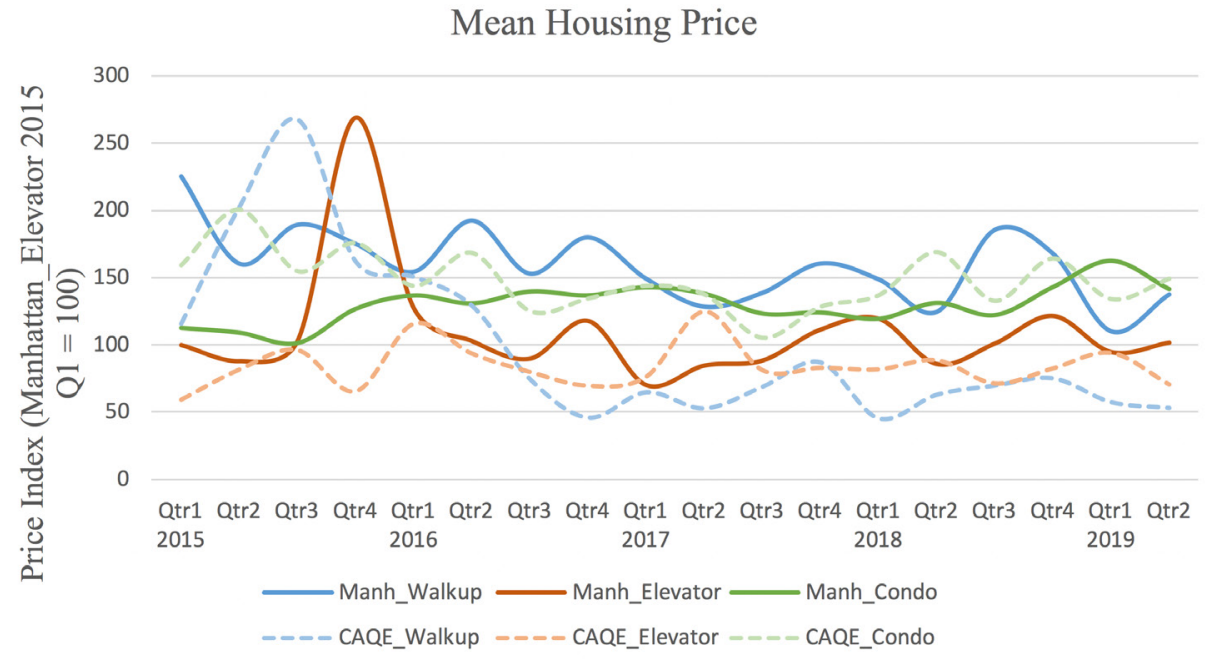

(b) by housing category/occupancy type

Figure 2. Histograms of quarterly mean housing price

Note: Price per square foot was converted to price index following Dube et al. (2018).

\subsection{Hedonic pricing model by housing types}

We examine the significant variables affecting housing prices. First, we run regressions on all housing transactions. Then, we run regression models on particular types of housing, including walkup co-ops, elevator co-ops, and condominiums. Table 3 shows the results of all residential transactions and by housing types.

For all residential transactions within the CAQE, structural characteristics including number of bathrooms, number of stories, and total units, are significant factors (at the $<0.001$ level) positively affecting the price per square foot. Building age is negatively associated with price. For amenity variables, having a gym, storage space, a pool, and children's playroom is positively associated with price. On the other hand, having a bike room, garden, and parking are negatively associated with price, which is counterintuitive. We suspect that these amenities are only provided for a particular type of housing 
while the more high-end residents can afford to have their own private bike room and garden and their own drivers. Proximity to a library and a hospital both have positive influences on price. So are distances to Central Park and the East River. Proximity to Q-line extension within $300 \mathrm{~m}$ and proximity to the adjacent metro stations (the Lexington Avenue line service by the 4, 5, 6, and 6 Express lines) within $450 \mathrm{~m}$ are negatively related to price.

For elevator co-ops, all structural characteristics are significant. Most of the amenity variables except the availability of pool are significant. We find the number of stories to be negatively related to price, and the building area is positively related to price. Being close to the Q-line extension $(0-450 \mathrm{~m})$ positively affects the price. Located 150 to $300 \mathrm{~m}$ of distance to the adjacent metro station is the most positively related to price, among proximity variables. On the other hand, located $150-300 \mathrm{~m}$ to the Lexington line is negatively related to price.

For walkup co-ops, only stories (positive) and total units (negative) of the structural characteristics are significant. Having parking space available is positively related to price. Location within $0-600 \mathrm{~m}$ distance to Q-line extension and $0-450 \mathrm{~m}$ to Lexington line is positively related to price. Compared to elevator co-ops, walkup co-ops show the closer to the metro station, the higher the price without variation. In addition, most of the amenity variables are not significant. The reason could be both the limited amenities provided by the smaller walkup properties and the relatively poor quality of the amenities. Moreover, people who live in the walkup buildings may not value or use the amenities as much as people from the elevator walk-ups.

For condominiums, all structural characteristics are positively related to price, except for number of bedrooms that is negatively related to price. Having a gym and children's playroom are positively related to price. Proximity to Q-line extension within $600 \mathrm{~m}$ is negatively significant, and so is proximity to Lexington line stations.

In sum, being close to the Q-line extension (located in the 0-150 and 150-300 m catchments) or the Lexington line stations (located in the $0-150,150-300$, and $300-450 \mathrm{~m}$ ) is negatively related to price. However, the variation among different housing types is also significant. Walkup co-ops exhibit positive associations with all proximate variables, while condominiums show negative associations. 
Table 3. Hedonic regression on housing property sales

\begin{tabular}{|c|c|c|c|c|c|c|c|c|c|c|c|c|}
\hline \multirow[b]{2}{*}{ Variable } & \multicolumn{3}{|c|}{ All Residential } & \multicolumn{3}{|c|}{ Elevator Co-ops } & \multicolumn{3}{|c|}{ Walkup Co-ops } & \multicolumn{3}{|c|}{ Condominium } \\
\hline & Coeff. & & Std Err. & Coeff. & & Std Err. & Coeff. & & Std Err. & Coeff. & & Std Err. \\
\hline Area & 0.0000 & & 0.0000 & 0.0000 & $* *$ & 0.0000 & 0.0000 & & 0.0000 & 0.0000 & $* *$ & 0.0000 \\
\hline Bed & 0.0090 & $*$ & 0.0045 & 0.0302 & $* * *$ & 0.0059 & 0.0331 & & 0.0286 & -0.0212 & $* * *$ & 0.0056 \\
\hline Bath & 0.1265 & $* * *$ & 0.0050 & 0.1201 & $* * *$ & 0.0066 & 0.0449 & & 0.0294 & 0.1370 & $* * *$ & 0.0064 \\
\hline Stories & 0.0049 & $* * *$ & 0.0003 & -0.0028 & $* * *$ & 0.0005 & 0.1271 & $* * *$ & 0.0276 & 0.0051 & $* * *$ & 0.0003 \\
\hline Total Unit & -0.0003 & $* * *$ & 0.0000 & 0.0001 & $* *$ & 0.0000 & -0.0219 & $* * *$ & 0.0029 & -0.0004 & $* * *$ & 0.0000 \\
\hline Age & -0.0016 & $* * *$ & 0.0001 & -0.0022 & $* * *$ & 0.0002 & -0.0014 & & 0.0009 & 0.0003 & * & 0.0001 \\
\hline Amenity_G & 0.1227 & $* * *$ & 0.0052 & 0.0963 & $* * *$ & 0.0064 & 0.0000 & & . & 0.1811 & $* * *$ & 0.0076 \\
\hline Amenity_P & 0.0133 & * & 0.0068 & 0.0076 & & 0.0100 & 0.0000 & & . & -0.0289 & $* * *$ & 0.0085 \\
\hline Amenity_Bi & -0.0860 & $* * *$ & 0.0046 & -0.0293 & $* * *$ & 0.0067 & -0.0464 & & 0.0405 & -0.0130 & $* *$ & 0.0062 \\
\hline Amenity_Ga & -0.0568 & $* * *$ & 0.0096 & 0.1048 & $* * *$ & 0.0133 & 0.0000 & & $\cdot$ & -0.0660 & $* * *$ & 0.0128 \\
\hline Amenity_St & 0.0311 & $* * *$ & 0.0048 & 0.0475 & $* * *$ & 0.0064 & 0.0772 & & 0.1064 & 0.0111 & & 0.0062 \\
\hline Amenity_Pa & -0.0833 & $* * *$ & 0.0051 & -0.1419 & $* * *$ & 0.0064 & 0.2494 & * & 0.1194 & 0.0124 & & 0.0073 \\
\hline Amenity_Pl & 0.1046 & $* * *$ & 0.0064 & -0.0620 & $* * *$ & 0.0123 & 0.0000 & & . & 0.0328 & $* * *$ & 0.0076 \\
\hline Dist_Cp & 0.0001 & $* * *$ & 0.0000 & 0.0001 & $* * *$ & 0.0000 & 0.0001 & & 0.0001 & 0.0001 & * & 0.0000 \\
\hline Dist_Er & 0.0006 & $* * *$ & 0.0000 & 0.0005 & $* * *$ & 0.0000 & -0.0001 & & 0.0001 & 0.0007 & $* * *$ & 0.0000 \\
\hline Dist-Q & -0.0001 & & 0.0000 & 0.0003 & $* * *$ & 0.0001 & 0.0023 & $* * *$ & 0.0003 & -0.0008 & $* * *$ & 0.0001 \\
\hline Library & 0.0376 & $* * *$ & 0.0059 & -0.0011 & & 0.0074 & -0.1499 & $* *$ & 0.0543 & 0.0236 & $* *$ & 0.0082 \\
\hline Hospital & 0.1200 & $* * *$ & 0.0105 & 0.0305 & * & 0.0145 & -0.1565 & & 0.0852 & 0.1239 & $* * *$ & 0.0130 \\
\hline Q0_150 & -0.1199 & $* * *$ & 0.0287 & 0.0813 & * & 0.0353 & 0.9316 & $* * *$ & 0.1962 & -0.4950 & $* * *$ & 0.0407 \\
\hline Q150_300 & -0.0989 & $* * *$ & 0.0223 & 0.1187 & $* * *$ & 0.0279 & 0.9387 & $* * *$ & 0.1441 & -0.4273 & $* * *$ & 0.0307 \\
\hline Q300_450 & -0.0101 & & 0.0157 & 0.0967 & $* * *$ & 0.0188 & 0.5646 & $* * *$ & 0.0959 & -0.2567 & $* * *$ & 0.0227 \\
\hline Q450_600 & -0.0477 & $* * *$ & 0.0097 & 0.0148 & & 0.0117 & 0.2756 & $* * *$ & 0.0602 & -0.1495 & $* * *$ & 0.0143 \\
\hline Q600_750 & - & & - & - & & - & - & & - & - & & - \\
\hline A0-150 & -0.1181 & $* * *$ & 0.0101 & -0.0139 & & 0.0155 & 0.3052 & * & 0.1353 & -0.1987 & $* * *$ & 0.0126 \\
\hline A150-300 & -0.1260 & $* * *$ & 0.0071 & -0.0594 & $* * *$ & 0.0089 & 0.3135 & $* * *$ & 0.0596 & -0.1844 & $* * *$ & 0.0103 \\
\hline A300-450 & -0.0255 & $* * *$ & 0.0059 & 0.0111 & & 0.0083 & 0.1816 & $* * *$ & 0.0491 & -0.0970 & $* * *$ & 0.0079 \\
\hline Intercept & 6.4372 & $* * *$ & 0.0473 & 6.2216 & $* * *$ & 0.0607 & 5.0260 & $* * *$ & 0.3332 & 6.9227 & $* * *$ & 0.0649 \\
\hline R-Square & & & 0.5401 & & & 0.4871 & & & 0.4240 & & & 0.5792 \\
\hline Adj R-Sq & & & 0.5395 & & & 0.4857 & & & 0.4006 & & & 0.5780 \\
\hline Root MSE & & & 0.2786 & & & 0.2451 & & & 0.2983 & & & 0.2447 \\
\hline
\end{tabular}

${ }^{* * *} \mathrm{p}<0.001,{ }^{* *} \mathrm{p}<0.01,{ }^{*} \mathrm{p}<0.05$

Note: All residential $n=20,050$; Elevator co-ops $n=9,977$; Walkup co-ops $n=565$; Condominium $n=9,450$. We included the variable Area as it is one of the most important characteristics of the housing property. We are aware of the endogeneity problem since the independent variable is price/area. We kept walkup co-ops (even though they contain a smaller sample) because it introduces a different housing type. 


\subsection{Spatial autocorrelation adjusted hedonic pricing model}

As discussed earlier, parallel to the Q-line extension, the Lexington Ave Line is two blocks away or less than 1,000 feet to the west. To separate the impact of Q-line and the already well-serviced Lexington Ave Line, it is necessary to run a hedonic regression by location - on the eastside versus the westside of the Q-line extension, see Figure 3. To examine spatial autocorrelation, we first identify spatial dependence in the data. Then we use $\mathrm{GeoDa}$, an open-source software package for spatial modeling, to reestimate the model with a maximum likelihood approach while controlling for the spatial dependence.

Table 4 shows the results of the spatial lag and error models. In these models, spatial lag and error terms are added. The r-square values for all models are relatively high. We can also see that both the lag and error terms are significant, indicating the presence of spatial dependence. The spatial lag and error models also show a negative association between proximity to the Q-line extension on the westside while showing a positive association on the eastside.

The structural characteristics, including the number of bathrooms and the number of stories, are positively correlated to the price at 0.001 level on both west and east sides. Total units and age of the building are both negatively significant at the 0.001 level. On the westside, the area of the unit is positively significant; on the eastside, the number of bedrooms is positively significant, both at the 0.001 level. Among the amenity variables, having a bike room is negatively associated with price, while having a pool is positively associated with the price on the westside. The only variable that shows a similar effect from both sides is having a children's playroom, which is positively significant. The neighborhood characteristics show that distance to the nearest Q-line station is significant on both sides. However, it is negative on the westside while positive on the eastside. Proximity to metro exhibit a dichotomy between the westside and the eastside: Locations within 0-150, 150-300, 300-450, and 450-600 $\mathrm{m}$ are all negative for the former and positive for the latter. Proximity to adjacent Lexington Ave Line stations is positively significant on the westside $(0-150,150-300$, and $300-450 \mathrm{~m})$ and the eastside (300-450 $\mathrm{m})$. Keep in mind one significant difference between the eastside and the westside is that the westside is served by another subway line. Further explanation will be provided in the discussion section. 
Table 4. Spatial lag and error models by location

\begin{tabular}{|c|c|c|c|c|c|c|}
\hline \multirow{2}{*}{$\begin{array}{l}\text { Lag+Error } \\
\text { Variable }\end{array}$} & \multicolumn{3}{|c|}{ Westside } & \multicolumn{3}{|c|}{ Eastside } \\
\hline & Coeff. & & Prob. & Coeff. & & Prob. \\
\hline Area & 0.0001 & $* * *$ & 0.0000 & 0.0000 & & 0.1868 \\
\hline Bath & 0.0865 & $* * *$ & 0.0000 & 0.0613 & $* * *$ & 0.0000 \\
\hline Bed & -0.0019 & & 0.7309 & 0.0504 & $* * *$ & 0.0000 \\
\hline Stories & 0.0052 & $* * *$ & 0.0000 & 0.0112 & $* * *$ & 0.0000 \\
\hline Total Unit & -0.0004 & $* * *$ & 0.0000 & -0.0008 & $* * *$ & 0.0000 \\
\hline Age & -0.0018 & $* * *$ & 0.0000 & -0.0006 & $* * *$ & 0.0004 \\
\hline Amenity_G & 0.1673 & $* * *$ & 0.0000 & -0.1047 & $* * *$ & 0.0000 \\
\hline Amenity_P & 0.0499 & $* * *$ & 0.0000 & 0.0058 & & 0.4479 \\
\hline Amenity_Bi & -0.0468 & $* * *$ & 0.0000 & 0.0151 & & 0.1292 \\
\hline Amenity_Ga & -0.0250 & & 0.0688 & -0.0424 & $* * *$ & 0.0005 \\
\hline Amenity_St & -0.0227 & $* * *$ & 0.0008 & 0.1363 & $* * *$ & 0.0000 \\
\hline Amenity_Pa & -0.0897 & $* * *$ & 0.0000 & -0.0239 & & 0.1740 \\
\hline Amenity_Pl & 0.0674 & $* * *$ & 0.0000 & 0.0236 & $* *$ & 0.0088 \\
\hline Dist_Cp & -0.0001 & * & 0.0119 & 0.0001 & & 0.9213 \\
\hline Dist_Er & 0.0002 & $* * *$ & 0.0000 & 0.0002 & & 0.6780 \\
\hline Dis_Q & -0.0005 & $* * *$ & 0.0000 & 0.0014 & $* * *$ & 0.0000 \\
\hline Library & - & & - & 0.1503 & & 0.4437 \\
\hline Hospital & -0.0253 & & 0.1565 & 0.0935 & $* * *$ & 0.0000 \\
\hline Q0_150 & -0.4024 & $* * *$ & 0.0000 & 0.6299 & $* * *$ & 0.0000 \\
\hline Q150_300 & -0.2305 & $* * *$ & 0.0000 & 0.6306 & $* * *$ & 0.0000 \\
\hline Q300_450 & -0.1257 & $* * *$ & 0.0000 & 0.5074 & $* * *$ & 0.0000 \\
\hline Q450_600 & -0.0992 & $* * *$ & 0.0000 & 0.2102 & $* * *$ & 0.0000 \\
\hline Q600_750 & - & & - & - & & - \\
\hline A0_150 & 0.0854 & $* * *$ & 0.0000 & - & & - \\
\hline A150_300 & 0.0495 & $* * *$ & 0.0004 & - & & - \\
\hline A300_450 & 0.1346 & $* * *$ & 0.0000 & 0.3107 & $* * *$ & 0.0000 \\
\hline Constant & 1.8480 & $* * *$ & 0.0000 & 5.7215 & $* * *$ & 0.0000 \\
\hline Spatial lag & 0.7271 & $* * *$ & 0.0000 & -0.0168 & & 0.8810 \\
\hline Spatial Error & 0.4073 & $* * *$ & 0.0000 & 0.9682 & $* * *$ & 0.0000 \\
\hline R-square & 0.5431 & & - & 0.4368 & & - \\
\hline
\end{tabular}

${ }^{* * *} \mathrm{p}<0.001,{ }^{* *} \mathrm{p}<0.01,{ }^{*} \mathrm{p}<0.05$

Note: All residential $n=20,050$; Elevator co-ops n=9,977; Walkup co-ops $n=565$; Condominium n=9,450. Eastside $\mathrm{n}=11,881$; Westside $\mathrm{n}=10,993$. 


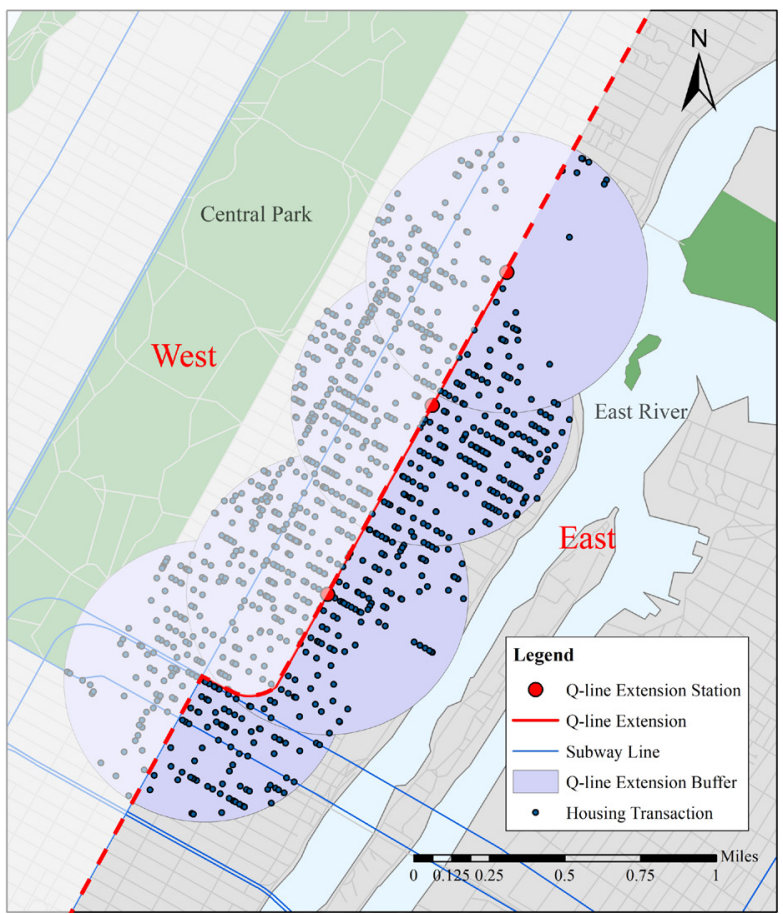

Figure 3. Property division based on location: eastside versus the westside of the Q-line extension

\subsection{Hedonic pricing model by year}

To observe anticipation and post-construction effect, we run hedonic pricing models by year. The results are shown in Table 5. On the westside, the location variables in the CAQE are all negatively significant, except for Q300-450 in 2016, and the coefficients follow a trend to become more negative. Location in the 0-150 m CAQE became negatively significant after the operation of the Q-line extension in 2017. Location in the 150-300 m CAQE became negatively significant one year after the operation. Location in the 300-450 m CAQE was positively significant right before the operation of the Q-line extension in 2016 and changed to negatively significant right after in 2017. Moreover, both the level of significance and the coefficients became more negative. On the eastside, however, the location variables in the CAQE $(0-600 \mathrm{~m})$ is positively related to price. Location in the $0-150 \mathrm{~m}$ catchment area was positively significant in 2014, and the sign changed to be negative in 2015. In the second year after the operation, the relationship changed again to be positive in 2018 and 2019. Locations in the $150-300 \mathrm{~m}$ and $300-450 \mathrm{~m}$ catchment areas were positively related to price in 2014,2018 , and 2019 . Location in the 450-600 m was negatively related to price in 2015 and 2016. However, the relation became positive in 2018 and 2019.

Locations in close proximity to the Lexington line stations $(0-150 \mathrm{~m}$ and $150-300 \mathrm{~m})$ were negatively significant in 2014 before the operation of the Q-line extension and again became negatively significant after the operation on the westside. On the eastside, location in the $300-450 \mathrm{~m}$ catchment area is positively significant in all years except 2015 . 
Table 5. Westside and eastside of the Q-line extension.

\begin{tabular}{|c|c|c|c|c|c|c|c|c|c|c|c|c|}
\hline Westside & 2014 & & 2015 & & 2016 & & 2017 & & 2018 & & 2019 & \\
\hline Variable & Coeff. & & Coeff. & & Coeff. & & Coeff. & & Coeff. & & Coeff. & \\
\hline Area & 0.0000 & $* *$ & 0.0001 & $* * *$ & 0.0001 & $* * *$ & 0.0001 & $* * *$ & 0.0000 & & 0.0001 & *** \\
\hline Bed & 0.0191 & & 0.0018 & & -0.0360 & * & -0.0098 & & -0.0084 & & 0.0004 & \\
\hline Bath & 0.0930 & $* * *$ & 0.0860 & $* * *$ & 0.0934 & $* * *$ & 0.0733 & $* * *$ & 0.0998 & $* * *$ & 0.0703 & $* * *$ \\
\hline Stories & 0.0109 & $* * *$ & 0.0107 & $* * *$ & 0.0082 & $* * *$ & 0.0096 & $* * *$ & 0.0039 & $* * *$ & 0.0002 & \\
\hline Total_Unit & -0.0025 & $* * *$ & -0.0010 & $* * *$ & -0.0006 & $* *$ & -0.0007 & $* * *$ & 0.0003 & $* * *$ & 0.0009 & $* * *$ \\
\hline Age & -0.0014 & $* * *$ & -0.0013 & $* * *$ & -0.0008 & * & -0.0005 & * & -0.0015 & $* * *$ & -0.0024 & $* * *$ \\
\hline Amenity_G & 0.1214 & $* * *$ & 0.1387 & $* * *$ & 0.1546 & $* * *$ & 0.1665 & $* * *$ & 0.1540 & $* * *$ & 0.1392 & $* * *$ \\
\hline Amenity_P & 0.4809 & $* * *$ & 0.1717 & $* * *$ & 0.1179 & $* *$ & 0.1904 & $* * *$ & 0.0768 & $* * *$ & 0.0025 & \\
\hline Amenity_Bi & -0.0043 & & 0.0085 & & 0.0134 & & -0.0740 & $* * *$ & -0.0711 & $* * *$ & -0.0823 & $* * *$ \\
\hline Amenity_Ga & -0.0735 & & -0.0257 & & 0.1676 & $* * *$ & 0.0105 & & -0.0886 & $* * *$ & -0.0425 & \\
\hline Amenity_St & 0.0487 & * & -0.0574 & $* *$ & -0.0369 & & -0.0490 & $* * *$ & -0.0432 & $* * *$ & -0.0874 & $* * *$ \\
\hline Amenity_Pa & 0.0553 & & -0.1070 & $* * *$ & -0.0533 & & -0.0869 & $* * *$ & -0.1391 & $* * *$ & -0.1278 & $* * *$ \\
\hline Amenity_Pl & 0.1494 & $* * *$ & 0.1003 & $* *$ & -0.0860 & $* *$ & 0.0094 & & 0.0732 & $* * *$ & 0.0865 & $* * *$ \\
\hline Dist_Cp & -0.0003 & $* *$ & -0.0003 & $* * *$ & 0.0000 & & 0.0001 & & -0.0003 & $* * *$ & -0.0007 & $* * *$ \\
\hline Dist_Er & 0.0008 & $* * *$ & 0.0008 & $* * *$ & 0.0008 & $* * *$ & 0.0008 & $* * *$ & 0.0005 & $* * *$ & 0.0004 & $* * *$ \\
\hline Dist-Q & -0.0010 & $* * *$ & -0.0002 & & 0.0002 & & -0.0007 & $* * *$ & -0.0007 & $* * *$ & -0.0015 & *** \\
\hline Library & 0.1441 & $* * *$ & 0.0509 & * & -0.0327 & & 0.0041 & & -0.0109 & & 0.0252 & \\
\hline Hospital & 0.0237 & & 0.0023 & & -0.0141 & & -0.1655 & $* * *$ & -0.0407 & & -0.0522 & \\
\hline Q0_150 & -0.5076 & $* * *$ & 0.0292 & & 0.1478 & & -0.3510 & $* * *$ & -0.4282 & $* * *$ & -0.6881 & $* * *$ \\
\hline Q150_300 & -0.2758 & $* *$ & 0.1351 & & 0.1259 & & -0.2237 & & -0.2853 & $* * *$ & -0.5264 & $* * *$ \\
\hline Q300_450 & -0.1566 & * & 0.0826 & & 0.1497 & * & -0.1144 & * & -0.1258 & $* *$ & -0.3086 & $* * *$ \\
\hline Q450_600 & -0.0744 & & 0.0626 & & 0.0195 & & -0.0695 & * & -0.0774 & $* *$ & -0.1455 & $* * *$ \\
\hline Q600_750 & - & & - & & - & & - & & - & & - & \\
\hline A0_150 & -0.1399 & $* *$ & 0.0468 & & 0.0556 & & -0.1022 & $* * *$ & -0.1153 & $* * *$ & -0.0831 & * \\
\hline A150_300 & -0.1532 & $* * *$ & -0.0398 & & -0.0230 & & -0.0714 & $* *$ & -0.0752 & $* * *$ & -0.0488 & \\
\hline A300_450 & -0.0589 & & 0.0173 & & 0.0725 & $* *$ & -0.0029 & & -0.0090 & & -0.0213 & \\
\hline Intercept & 6.9541 & $* * *$ & 6.3234 & $* * *$ & 5.9655 & $* * *$ & 6.5600 & $* * *$ & 7.1636 & $* * *$ & 7.9432 & $* * *$ \\
\hline
\end{tabular}

${ }^{* * *} \mathrm{p}<0.001,{ }^{* *} \mathrm{p}<0.01,{ }^{*} \mathrm{p}<0.05$

\begin{tabular}{lcccccccccccc}
\hline Eastside & 2014 & & 2015 & & 2016 & & 2017 & & 2018 & & 2019 \\
Variable & Coeff. & & Coeff. & & Coeff. & & Coeff. & Coeff. & \multicolumn{2}{c}{ Coeff. } \\
\hline Area & 0.0000 & $* * *$ & 0.0001 & $* * *$ & 0.0000 & $* *$ & 0.0000 & 0.0000 & & 0.0000 & \\
Bed & 0.0403 & $*$ & 0.0132 & & 0.0140 & & -0.0048 & & 0.0227 & $*$ & 0.0388 & $* *$ \\
Bath & 0.0882 & $* * *$ & 0.0794 & $* * *$ & 0.1252 & $* * *$ & 0.1153 & $* * *$ & 0.0943 & $* * *$ & 0.0451 & $* *$ \\
Stories & 0.0048 & $* * *$ & 0.0093 & $* * *$ & 0.0072 & $* * *$ & 0.0096 & $* * *$ & 0.0060 & $* * *$ & 0.0063 & $* * *$ \\
Total_Unit & -0.0007 & $* * *$ & -0.0007 & $* * *$ & -0.0005 & $* * *$ & -0.0003 & $* * *$ & -0.0003 & $* * *$ & -0.0002 & $* *$ \\
Age & -0.0006 & $*$ & -0.0015 & $* * *$ & -0.0030 & $* * *$ & -0.0015 & $* * *$ & -0.0032 & $* * *$ & -0.0041 & $* * *$ \\
\hline Amenity_G & 0.1872 & $* * *$ & 0.1402 & $* * *$ & 0.0554 & & 0.0802 & $* * *$ & -0.0107 & & 0.0117 & \\
Amenity_P & -0.1645 & $* * *$ & -0.1182 & $* * *$ & -0.0205 & & 0.0228 & & -0.0528 & $* * *$ & -0.0699 & $* * *$ \\
Amenity_Bi & -0.1110 & $* * *$ & 0.0065 & & -0.0535 & $* * *$ & -0.0743 & $* * *$ & -0.1291 & $* * *$ & -0.0904 & $* * *$ \\
Amenity_Ga & -0.2680 & $* * *$ & -0.2213 & $* * *$ & -0.1078 & $* * *$ & -0.0266 & & 0.0569 & $*$ & 0.0023 &
\end{tabular}




\begin{tabular}{|c|c|c|c|c|c|c|c|c|c|c|c|c|}
\hline Eastside & 2014 & & 2015 & & 2016 & & 2017 & & 2018 & & 2019 & \\
\hline Variable & Coeff. & & Coeff. & & Coeff. & & Coeff. & & Coeff. & & Coeff. & \\
\hline Amenity_St & -0.0425 & & -0.0063 & & 0.0240 & & 0.0551 & $* * *$ & 0.1043 & $* * *$ & 0.0956 & $* * *$ \\
\hline Amenity_Pa & 0.0321 & & -0.1026 & $* * *$ & -0.0865 & $* * *$ & -0.0175 & & -0.0371 & $* * *$ & -0.0770 & $* * *$ \\
\hline Amenity_Pl & 0.1175 & $* * *$ & 0.0367 & & 0.0939 & $* * *$ & 0.0619 & $* * *$ & 0.1803 & $* * *$ & 0.1656 & $* * *$ \\
\hline Dist_Cp & -0.0004 & $* * *$ & -0.0002 & $* *$ & 0.0001 & & 0.0001 & & 0.0005 & $* * *$ & 0.0006 & $* * *$ \\
\hline Dist_Er & 0.0000 & & 0.0002 & & 0.0004 & $* * *$ & 0.0005 & $* * *$ & 0.0006 & $* * *$ & 0.0009 & $* * *$ \\
\hline Dist-Q & 0.0011 & $* * *$ & -0.0002 & & 0.0000 & & 0.0005 & $* * *$ & 0.0006 & $* * *$ & 0.0005 & $* * *$ \\
\hline Library & 0.0522 & * & 0.1189 & $* * *$ & 0.1118 & $* * *$ & 0.0248 & & 0.1582 & $* * *$ & 0.1170 & $* * *$ \\
\hline Hospital & 0.0523 & & 0.1214 & $* *$ & 0.0701 & & 0.1488 & $* * *$ & 0.1255 & $* * *$ & 0.2060 & $* * *$ \\
\hline Q0_150 & 0.4162 & $* * *$ & -0.2336 & $*$ & -0.1263 & & 0.0790 & & 0.4294 & $* * *$ & 0.3366 & $* * *$ \\
\hline Q150_300 & 0.3118 & $* *$ & -0.1384 & & -0.1045 & & 0.0597 & & 0.4182 & $* * *$ & 0.3563 & $* * *$ \\
\hline Q300_450 & 0.1517 & * & -0.0540 & & -0.0358 & & 0.0391 & & 0.3322 & $* * *$ & 0.3136 & $* * *$ \\
\hline Q450_600 & 0.0399 & & -0.0994 & $* *$ & -0.0649 & $*$ & -0.0071 & & 0.1843 & $* * *$ & 0.1627 & $* * *$ \\
\hline Q600_750 & - & & - & & - & & - & & - & & - & \\
\hline A300_450 & 0.1183 & $* * *$ & -0.0082 & & 0.0710 & $* *$ & 0.0956 & $* * *$ & 0.1518 & $* * *$ & 0.0940 & $* *$ \\
\hline Intercept & 6.5658 & $* * *$ & 7.0580 & $* * *$ & 6.7345 & $* * *$ & 6.2407 & $* * *$ & 5.6078 & $* * *$ & 5.3612 & $* * *$ \\
\hline
\end{tabular}

${ }^{* * *} \mathrm{p}<0.001,{ }^{* *} \mathrm{p}<0.01,{ }^{*} \mathrm{p}<0.05$

Note: All residential n=20,050; Elevator co-ops n=9,977; Walkup co-ops n=565; Condominium n=9,450. Eastside $\mathrm{n}=11,881$; Westside $\mathrm{n}=10,993$.

\section{Discussion}

This study reveals that prices for different housing types react differently to the Q-line extension. Among the structural characteristics and amenity variables, elevator co-ops often exhibit opposite signs of significance compared to walkup co-ops and condominiums. For example, the number of stories and a parking space are negatively related to the price for elevator co-ops but positively related to the other two housing types. We, unfortunately, do not know the exact location of units within buildings, so we do not know which units have views of Central Park. One possible solution is to remove the transactions on 5th Ave. We observed that the condominiums in close proximity to the Q-line catchment areas exhibit a negative correlation to price while the other two housing types are positive, and the closer the condominiums to the Q-line extension (0-150 m), the higher the price discount yielded. On the other hand, walkup co-ops in close proximity to the Lexington line catchment areas show a positive correlation to price while the other two housing types are negative. We argue that the reason for the discrepancy is due to the different demographic populations that were occupying the housing units. It is possible that the condominium users are generally vehicle owners or taxi/shared ride users who place less value on metro accessibly than on quietness and safety. Elevator and walkup users, on the other hand, may place value more on increased metro accessibility. Acquiring occupier data will be informative to understand the causality in future studies. Nevertheless, it is important to consider both occupancy type and building form are important factors for better understanding the effect of metro extension on housing price. There are other variables that might affect the results. For example, some properties are closer to 5 th avenue facing Central Park.

The existing Lexington line makes it difficult to separate the effect of metro access of Q-line extension. In addition to adding the distance dummy variables, we also control spatial autocorrelation by dividing housing transactions into westside and eastside of the Q-line extension. The results show that 
on the eastside, where accessibility to Lexington line stations is low, location in the catchment areas of Q-line extension is positively significant. On the westside, the opposite holds true. The dichotomy of westside versus eastside shows that it is necessary to consider location variation when other metro stations exist in the study area of new extension lines.

For the westside properties, the price discount in close proximity to the Q-line extension $(0-$ $150 \mathrm{~m}$ ) was increasingly higher each year since its operation. This may be explained by the fact that the westside properties already benefited from the adjacent Lexington Avenue line so that the new metro extension not only provided little additional benefit but also brought more people to the neighborhood. The increasing price premium in closer proximity to the new metro extension on the eastside properties could be explained by the increasing convenience of metro access. The temporal regression we implemented in this study does contain limitations in its nature of dividing the properties dataset according to time variables.

This study also observes location variation of time-lag effects. On the westside, housing transactions in close proximity to the Q-line extension stations $(0-150 \mathrm{~m})$ show two-year negative market anticipation before the operation. Location in the 150-300 m catchment shows both two-year negative market anticipation and one-year negative post operation effect. However, locations in the 300-450 and 450$600 \mathrm{~m}$ catchment areas do not show a time-lag effect. On the eastside, locations in all catchment areas $(0-150,150-300,300-450$, and 450-600 m) show a two-year negative market anticipation effect and one-year positive post-operation effects. These results show that market anticipation or time lag effects of housing price change can occur before or after the operation of the metro station investment. This is through word of mouth, an image posted online, or related infrastructure investment, in addition to information imbalance and market imperfection. Furthermore, after metro stations become operational and cleaning up of the construction sites, anticipation effects or time lags can also occur. This is related to the construction methods, such as cut and cover, see Appendix C. After the post-construction cleanup period when accessibility improvement is realized, time lag effects exist as a delay. In our study, the anticipation of prices is largely based on when the project will be finished.

\section{Conclusion}

In this paper, we study the impact of metro extension on housing prices. We find that housing type, spatial variation, and market anticipation are essential factors in how metro extension affects housing price. The results indicate price premiums for elevator co-ops and walkup co-ops in close proximity to stations and price discounts for condominiums. After controlling for location variation, we observe price premiums on the westside and price discounts on the eastside post construction. The anticipation effect varies by distance to metro extension stations, both before and after the operation. The disruption of metro construction on the housing market depends on housing type, location variation, and changes over time. In comparison to the existing studies, our paper demonstrates a negative housing price effect in close proximity to the metro line extension. Our study also observed that different housing typologies exerted the impact of metro accessibility differently, which may be explained by the diverse housing occupiers and to be validated in future studies. Additionally, we found a distinct location variation of the time lag effect, which indicates that market anticipation of housing price change can occur before or after the operation of the metro expansion. Planners should consider various time-lag effects in different areas ahead of time when planning metro expansions.

Our research makes the following contributions: it takes the first attempt to study the marginal valuations of proximity to metro extension stations as capitalized in property prices in the center of a major global metropolis. Second, it demonstrates a temporal variation of the price premium and discount 
when being in close proximity to metro extension stations with various anticipation effects exerted on local housing value. The third contribution is the application of a variety of spatial models to detect the location variation of different housing submarkets.

Limitations of this study and future works are the following: Concerning spatial variations, each station can be different, for example, with respect to passenger flow volume and the development intensity around the station (Devaux et al., 2017; Hess \& Almeida, 2007) -- We did not reflect the distinctive impact of station-specific conditions. Regarding temporal impact, interacting the year dummy variables with the dependent variable can provide an effective validation for the regressions per year and a more suitable time series model should also be deployed to address such limitations. In future studies, we plan to use control groups and rental markets to decompose the effect of metro line extensions. Additionally, using a network distance or time distance can further improve the accuracy of the results compared to using the Euclidean distance to measure proximity to metro stations and amenities. The application of repeated sales data can also yield additional results on metro construction on housing prices.

\section{Acknowledgements}

This article is funded by the PEAK Urban programme, supported by UKRI's Global Challenge Research Fund, Grant Ref: ES/P011055/1; supported by Open Projects Fund of Shanghai Key Laboratory of Urban Renewal and Spatial Optimization Technology, Grant Ref. 2020030201;

the NYUAD Center for Interacting Urban Networks (CITIES), funded by Tamkeen under the NYUAD Research Institute Award CG001 and by the Swiss Re Institute under the Quantum Cities ${ }^{\mathrm{TM}}$ initiative; and sponsored by the Zaanheh Project, the Center for Data Science and Artificial Intelligence, the Center for Applied Social and Economic Research (CASER), and the NYU Shanghai Urban Lab at NYU Shanghai and the Shanghai Pujiang Program, Grant Ref. 2019PJC076. 


\section{References}

Agostini, C. A., \& Palmucci, G. A. (2008). The anticipated capitalization effect of a new metro line on housing prices. Fiscal Studies, 29(2), 233-256.

Alonso, W. (1964). Location and land use: Toward a general theory of land rents. Cambridge, MA: Harvard University Press.

Anselin, L. \& Bera, A. K. (1998). Spatial dependence in linear regression models with an introduction to spatial econometrics. In A. Ullah (Ed.), Handbook of applied economic statistics (pp. 237-290). Boca Raton, FL: CRC Press.

Atkinson-Palombo, C. (2010). Comparing the capitalization benefits of light-rail transit and overlay zoning for single-family houses and condos by neighborhood type in metropolitan Phoenix, Arizona. Urban Studies, 47(11), 2409-2426.

Cao, K., Diao, M., \& Wu, B. (2019). A big data-based geographically weighted regression model for public housing prices: A case study in Singapore. Annals of the American Association of Geographers, 109(1), 173-186.

Cervero, R. (2006). Effects of light and commuter rail transit on land prices: Experiences in San Diego County. Berkeley, CA: University of California Transportation Center.

Comber, S. \& Arribas-Bel, D. (2017). Waiting on the train: The anticipatory (causal) effects of cross rail in Ealing. Journal of Transport Geography, 64, 13-22.

City of New York. (2019). Building classification. https:/www1.nyc.gov/assets/finance/jump/hlpbldgcode.html

Dai, X., Xin B., \& Min X. (2016). The influence of Beijing rail transfer stations on surrounding housing prices. Habitat International, 55, 79-88.

Debrezion, G., Pels, E., \& Rietveld, P. (2011). The impact of rail transport on real estate prices: An empirical analysis of the Dutch housing market. Urban Studies, 48(5), 997-1015.

Deng, L. \& Chen, J. (2019). Market development, state intervention, and the dynamics of new housing investment in China. Journal of Urban Affairs, 41(2), 223-247.

Department of Finance. (2019). New York City. https://www1.nyc.gov/site/finance/taxes/propertyrolling-sales-data.page

Devaux, N., Dube, J. \& Apparicio, P. (2017). Anticipation and post-construction impact of a metro extension on residential values: The case of Laval (Canada), 1995-2013. Journal of Transport Geography, 62, 8-19.

Diao, M. (2015). Selectivity, spatial autocorrelation and the valuation of transit accessibility. Urban Studies, 52(1), 159-77.

Diao, M., Leonard, D., \& Sing, T. F. (2017). Spatial-difference-in-differences models for impact of new mass rapid transit line on private housing values. Regional Science and Urban Economics, 67, 64-77.

Duncan, M. (2008). Comparing rail transit capitalization benefits for single-family and condominium units in San Diego, California. Transportation Research Record: Journal of the Transportation Research Board, 2067(1), 120-30.

Dube, J., Legros, D., \& Devaux, N. (2018). From bus to tramway: Is there an economic impact of substituting a rapid mass transit system? An empirical investigation accounting for anticipation effect. Transportation Research Part A: Policy and Practice, 110, 73-87.

Dube, J., Thériault, M., \& Des Rosiers, F. (2013). Commuter rail accessibility and house values: The case of the Montreal South Shore, Canada, 1992-2009. Transportation Research Part A: Policy and Practice, 54, 49-66.

Gordon, B. L., \&Winkler, D. T. (2019). New house premiums, market conditions, and the decision to purchase a new versus existing house. Journal of Real Estate Research, 41(3), 379-410. 
Guan, C, \& Peiser, R. (2018). Accessibility, urban form, and property value: A study of Pudong, Shanghai. Journal of Transport and Land Use, 11(1), 1057-1080.

Guan, C., \& Rowe, P. (2021). China's urban block structures: A comparative study in three cities across different territories. Socio-Ecological Practice Research, 3, 37-53.

Harjunen, O. (2018). Essays in urban economics and housing market capitalization. Aalto University Press, $119,13$.

Hess, B. \& Almeida, T. (2007). Impact of proximity to light rail rapid transit on station-area property values in Buffalo, New York. Urban Studies, 44(5/6), 1041-1068.

Hiseh, L., \& Noonan, D. (2018). The closer the better? Examining support for a large urban redevelopment project in Atlanta. Journal of Urban Affairs, 40(2), 246-260.

Kaneko, Y., Nakagawa, T., Phun, V., \& Kato, H. (2019). Impacts of urban railway investment on regional economies: Evidence from Tokyo using spatial difference-in-differences analysis. Transportation Research Record: Journal of the Transportation Research Board, 2673(10), 129-140. https://doi. org/10.1177/0361198119846098

Kay, A., Noland, R., \& DiPetrillo, S. (2014). Residential property valuations near transit stations with transit-oriented development. Journal of Transport Geography, 39(C), 131-140.

Kim, K., \& Lahr, M. L. (2014). The impact of Hudson-Bergen light rail on residential property appreciation. Regional Science, S1, 79-97.

Kopczewska, K., and Lewandowska, L. (2018). The price for subway access: Spatial econometric modelling of office rental rates in London. Urban Geography, 39(10), 1528-554. https://doi.org/10.1080 /02723638.2018.1481601

Landis, J., Guhathukurta, S., Huang, W., Zhang, M., \& Fukuji, B. (1995). Rail transit investments, real estate values, and land use change: A comparative analysis of five California rail transit systems (Research Report No. 48). Berkeley, CA: Institute of Urban and Regional Studies, University of California.

Lesage, J., \& Pace, K. (2009). Introduction to spatial econometrics. Boca Raton, FL: CRC press.

Lewis-Workman, S., \& D. Brod. (1997). Measuring the neighborhood benefits of rail transit accessibility. Transportation Research Record: Journal of the Transportation Research Board, 1576, 147-153.

Lin, J. Y., Chen, T. L. \& Han, Q. Z. (2018). Simulating and predicting the impacts of light rail transit systems on urban land use by using cellular automata: A case study of Dongguan, China. Sustainability, 10(4), 1293.

Liou, F. M., Yang, S. Y., Chen, B. \& Hsieh, W. P. (2016). The effects of mass rapid transit station on the house prices in Taipei: The hierarchical linear model of individual growth. Pacific Rim Property Research Journal, 22, 3-16.

Martínez, L., \& Viegas, J. (2009). Effects of transportation accessibility on residential property values. Transportation Research Record: Journal of the Transportation Research Board, 2115(1), 127-137.

McDonald, J. F., \& Osuji, C. I. (1995). The effect of anticipated transportation improvement on residential land values. Regional Science \& Urban Economics, 25(3), 261-278.

McMillen, D. P. (2006). Testing for monocentricity. In R. J. Arnott, \& D. P. McMillen (Eds.), A companion to urban economics (pp. 128-140). Oxford, UK; Blackwell.

Miller, N, Sah, V., \& Sklar, M. K. (2018). Estimating property condition effect on residential property value: Evidence from U.S. home sales data. Journal of Real Estate Research, 40(2), 179-198.

Pan, Q., Pan H., et al. (2014). Effects of rail transit on residential property values. Transportation Research Record: Journal of the Transportation Research Board, 2453(1), 118-127.

Rodriguez, D., \& Mojica, C. (2009). Capitalization of BRT network expansions effects into prices of non-expansion areas. Transportation Research Part A: Policy and Practice, 43(5), 560-571.

Spears, S., Boarnet, M. G., \& Houston, D. (2017). Driving reduction after the introduction of light 
rail transit: Evidence from an experimental-control group evaluation of the Los Angeles Expo Line. Urban Studies, 54(12), 2780-2799.

Valente, J., Wu, S., Gelfand, A., \& Sirmans, C. F. (2005). Apartment rent prediction using spatial modeling. Journal of Real Estate Research, 27(1), 105-136.

Wang, Y. M., Feng, S. W., Deng, Z. W. \& Cheng, S. Y. (2016). Transit premium and rent segmentation: A spatial quantile hedonic analysis of Shanghai Metro. Transport Policy, 51, 61-69.

Xu, T., Zhang, M., Aditjandra, P. (2016). The impact of urban rail transit on commercial property value: New evidence from Wuhan, China. Transportation Research Part A: Policy and Practice 91, 223-235. https://doi.org/10.1016/j.tra.2016.06.026

Zhang, X., Liu, X. X., Hang, J. Q., Yao, D. B., \& Shi, G. P. (2016). Do urban rail transit facilities affect housing prices? Evidence from China. Sustainability, 8(4), 380.

Zhong, H., \& Li, W. (2016). Rail transit investment and property values: An old tale retold. Transport Policy, 51, 33-48.

\section{Appendices}

Appendices available at https:/www.jtlu.org/index.php/jtlu/article/view/1915. 